\title{
Polypharmacy and Potential Drug-Drug Interactions in Home-Dwelling Older People - A Cross-Sectional Study
}

This article was published in the following Dove Press journal: Journal of Multidisciplinary Healthcare

\author{
Monica Hermann (D)' \\ Nina Carstens ${ }^{2}$ \\ Lars Kvinge \\ Astrid Fjell (iD) ${ }^{1,3}$ \\ Marianne Wennersberg ${ }^{4}$ \\ Kjersti Folleso (iD ${ }^{5}$ \\ Knut Skaug ${ }^{6}$ \\ Ake Seiger $^{7}$ \\ Berit Seiger Cronfalk ${ }^{3,8}$ \\ Anne-Marie Bostrom (1) ${ }^{1,3,9}$ \\ 'Department of Health and Caring \\ Sciences, Western Norway University of \\ Applied Sciences, Stord, Norway; \\ ${ }^{2}$ Hospital Pharmacies Enterprise, \\ Western Norway, Bergen, Norway; \\ ${ }^{3}$ Department of Neurobiology, Care \\ Sciences and Society, Division of Nursing, \\ Karolinska Institutet, Stockholm, Sweden; \\ ${ }^{4}$ FOUSAM, Western Norway University \\ of Applied Sciences, Haugesund, Norway; \\ ${ }^{5}$ Bømlo Municipality, Hordaland, Norway; \\ ${ }^{6}$ Department of Research and Innovation, \\ Helse Fonna HF, Haugesund, Norway; \\ ${ }^{7}$ Division of Clinical Geriatrics, \\ Department of Neurobiology, Care \\ Sciences and Society, Karolinska \\ Institutet, Stockholm, Sweden; \\ ${ }^{8}$ Department of Health Care Sciences, \\ Palliative Research Centre Ersta Sköndal \\ Bräcke University College, Stockholm, \\ Sweden; ${ }^{9}$ Theme Aging, Karolinska \\ University Hospital, Huddinge, Sweden
}

Correspondence: Monica Hermann Tel + 4753491477

Email monica.hermann@hvl.no
Background: Risks associated with polypharmacy and drug-drug interactions represent a challenge in drug treatment, especially in older adults. The aim of the present study was to assess the use of prescription and non-prescription drugs and the frequency of potential drug-drug interactions in home-dwelling older individuals.

Methods: A cross-sectional study design was applied. Data were collected during preventive home visits among individuals aged $\geq 75$ in three separate communities of Western Norway. A questionnaire, which was filled out by the individual, their next-of-kin, and the nurse performing the home visit was used for the collection of demographic and clinical data (age, sex, medication use, diagnoses, need of assistance with drug administration). Potential drug-drug interactions were identified electronically by IBM Micromedex Drug Interaction Checking. Point prevalence of potential drug-drug interactions and polypharmacy ( $\geq 5$ drugs) were calculated. Binary logistic regression analyses were performed to assess factors potentially associated with polypharmacy or potential drug-drug interactions.

Results: Among the 233 individuals (mean age $78 \pm 3$ years, $46 \%$ male) included in the study, $43 \%$ used $\geq 5$ drugs, $3.4 \% \geq 10$ drugs, while $4.3 \%$ used no drugs. In $54 \%$ of the 197 individuals using two or more drugs, at least one potential drug-drug interaction was detected. Low-dose aspirin and simvastatin were most frequently involved in potential drug-drug interactions. In total, $25 \%$ of the individuals reported current use of drugs sold over the counter of which more than $95 \%$ were analgesic drugs. Potential drug-drug interactions involving ibuprofen were identified in nine of 11 (82\%) individuals using over-the-counter ibuprofen.

Conclusion: The study revealed a high prevalence of polypharmacy and potential drug-drug interactions with both prescription and non-prescription drugs in older home-dwelling individuals. Close monitoring of the patients at risk of drug-drug interactions, and increased awareness of the potential of over-the-counter drugs to cause drug-drug interactions, is needed.

Keywords: drug-drug interactions, polypharmacy, home-dwelling, old people

\section{Introduction}

Polypharmacy in older people is frequent, and recent data from the Norwegian Prescription Database has shown that $23 \%$ of the prescription drug users 65 years and older were prescribed 10 or more drugs in $2017 .{ }^{1}$ Polypharmacy in older people is a double-edged sword. Many drugs are crucial in the treatment of diseases, and relief of symptoms, in multimorbid older individuals. Concomitantly, polypharmacy is associated with increased risk of drug-drug interactions and adverse events leading to functional decline, hospital admission, and even death. ${ }^{2-4}$ Adverse events related to drug use are estimated to cause around $10 \%$ of hospital admissions in older people. ${ }^{2}$ 
Drug-drug interactions (DDIs) occur when the effect of a drug is affected by a concomitantly administered second drug. The result of drug-drug interactions can be either decreased effect of the affected drug or enhanced effect, and consequently increased risk of side-effects. The frequency of DDIs increases with increasing number of drugs. ${ }^{5}$ The reported frequencies of DDIs in observational studies vary between $15 \%$ and $70 \%$ depending on the characteristics of the study participants (age, morbidity), the setting, and assessment of potential DDIs. ${ }^{5-10}$

Through the last decades, increasing attention has been drawn towards improving drug prescription in older individuals. This has resulted in increased use of clinical decision support systems for prescribers, and increased use of structured medication reviews. In Norway, all inhabitants are assigned a regular general practitioner. The regular general practitioner is responsible for the coordination of the patients' drug treatment and performing a medication review when needed in patients with polypharmacy. ${ }^{11}$ Both clinical decision support systems and systematic medication reviews have been shown to reduce negative health outcomes from multiple drug use by reducing potentially serious DDIs and adverse drug reactions. $^{12,13}$

Despite the use of decision support systems and medication reviews, there is a risk of DDIs, especially for patients where multiple prescribers are involved in drug prescription. ${ }^{14}$ This is likely to be the case for homedwellers, as they may visit other medical doctors such as different specialists, practitioners at the out-of-hours emergency primary health care or hospitals, in addition to their regular general practitioner. A Norwegian multicenter study from 2015 showed discrepancies in up to $80 \%$ of medication lists upon hospital admission, illustrating the challenge of information transfer. ${ }^{15}$ Since 2012 there have been ongoing national efforts to develop a common system for electronic patient records across levels of the health care sector in Norway, but full implementation is still years away. ${ }^{16}$ Therefore, the transfer of patient information between levels will remain a challenge for several years to come. Also, self-medication with over-the-counter (OTC) drugs is frequent in older people with a prevalence of around $40 \%$ in western countries. ${ }^{17,18}$ Previous studies have shown that common OTC drugs like aspirin and other non-steroid anti-inflammatory drugs (NSAIDs) are frequently involved in DDIs, and are also the drugs most commonly involved in DDIs leading to hospital admission. ${ }^{4,5,19}$ The use of OTC drugs, therefore, adds to the total risk of potential DDIs. This is a challenge in general practice, as self-medication with OTC drugs are often not recorded in electronic patient records. ${ }^{20}$ Also, most studies on the consequences of drug-drug interactions for hospitalization or visits to the emergency department are based on medical records, and OTC drugs are therefore often ignored when evaluating drug-drug interactions. ${ }^{19}$ On this basis, we aimed to assess the use of prescription and non-prescription drugs and the frequency of potential drug-drug interactions in a cross-sectional study with home interviews of older home-dwelling individuals.

\section{Methods}

\section{Study Design and Data Collection}

A cross-sectional study design with preventive home-visits in home-dwelling older individuals was applied. ${ }^{21}$ Older home-dwelling inhabitants of three different nonneighboring municipalities, one urban and two rural municipalities of different sizes, situated in Western Norway, were invited to receive a preventive home visit. The three municipalities were selected as they were starting up a preventive home visit program (ie, convenience sampling). The visits aimed to identify persons at risk of developing illness by addressing four focal areas; malnutrition, falls, cognitive impairment, and polypharmacy. The home visit program has previously been described in detail. ${ }^{21}$ Briefly, older home-dwellers able to communicate in Norwegian were eligible for inclusion. In the smaller community, all individuals 75 years of age and above were included in the preventive home visit program, while in the two larger communities only home-dwellers 77 years of age were invited to receive a preventive home visit. The individuals were identified by the Norwegian National Registry, contacted by telephone, and asked to participate in the study. Approximately $60 \%$ of the invited individuals agreed to participate. ${ }^{21}$ The preventive home visits were performed by specially trained nurses. The nurses collected data using a questionnaire, which consisted of a substantial number of questions and validated tests on cognitive function, balance/falls, nutrition, and polypharmacy, in addition to questions on demographics, lifestyle, and medical diagnoses. ${ }^{21}$ For the focal area polypharmacy, the individual's age, sex, place of living (urban/rural), prescription and non-prescription drugs, medical diagnoses, and need for help with administration of medication were registered. Data on the use of prescription and non- 
prescription medication was collected during the home visit by a combination of sources; interview with participant and next-of-kin, visual inspection of medication after asking the participants to show the medication they were using, and written information in form of a medication list issued by the individuals' general practitioner (available for $23 \%$ of the participants) or home care nursing service $(11 \%)$.

\section{Data Analysis}

Two of the authors screened for drug-drug interactions. IBM Micromedex ${ }^{\circledR}$ Drug Interaction Checking (electronic version) was selected as knowledge base to identify potential drug-drug interactions, based on previous reports on accuracy and comprehensiveness. ${ }^{22-24}$ In the presentation of the results, the term potential drug-drug interaction (pDDI) is used, as many drug-drug interactions are avoidable and manageable with dose adjustments and/or close clinical follow-up and we do not have data on the consequence of the pDDI in the individual patient. PDDIs were classified in accordance with the classification system of Micromedex as either; contraindicated, major (interaction may be life-threatening or require medical intervention to minimize or prevent adverse effects), or moderate (the interaction may result in exacerbation of the patient's condition and/or require an alteration on therapy). The primary and secondary endpoints were point-prevalences of pDDIs and polypharmacy, respectively. Polypharmacy was defined as the use of five or more drugs. ${ }^{25}$ All participants were included in the analysis of point prevalence of polypharmacy, while only individuals using 2 or more drugs were included in the calculations of point-prevalence of $\mathrm{pDDIs.}$

The study sample was described in terms of demographics (age, sex, place of living (urban/rural), diagnoses, need for help with medicine administration), polypharmacy and drug-drug interactions using mean and standard deviation for continuous variables and frequencies and percentages for categorical variables. Binary logistic regression analyses were used to assess factors potentially associated with polypharmacy, and drug-drug interactions. Age, sex, place of living (urban/rural), "need help with medicines" (yes/no) and clinical diagnose were investigated as potential covariates in the analysis of polypharmacy. In the analysis of pDDIs, the total number of medications was also included as a potential covariate. The category "need help with medicines" included individuals that received help with administration of medicines from their next-of-kins or home care nurses. Diagnose categories were collapsed to reduce the number of independent variables and increase the frequency of positive outcomes in each category. Diagnose categories with less than $10 \%$ positive outcomes (ie, less than persons with the disease) were not included in the regression models. The included diagnose categories were as follows: diabetes, cardiovascular disease (hypertension, hyperlipidemia, heart failure, coronary heart disease), lung disease (chronic obstructive pulmonary disease and asthma), cancer, musculoskeletal disorders (osteoporosis, arthritis). Preliminary analyses were performed to ensure that the variables were not subjected to multicollinearity. The ratio of cases to variables in the logistic regression analysis was above 20. As there were no variables with a positive response rate of less than $10 \%$, the sample size was considered sufficient for this analysis. A p-value $<0.05$ was considered a statistically significant difference. SPSS version 27 (IBM Corporation, Armonk, NY, USA) was used for statistical analyses.

\section{Results}

In total, data from 233 home-dwellers were included, 109 from the urban community and 124 from the rural communities. The mean age of the participants was $78 \pm 3$ years and $46 \%$ were male. Hypertension and hyperlipidemia were the two most common diagnoses, affecting 52\% and $43 \%$ of the individuals, respectively (Table 1).

\section{Polypharmacy}

The median number of drugs was 4 (range 0-15) and polypharmacy was registered for 102 individuals (43\%). Eight individuals $(3.4 \%)$ used 10 or more drugs while $10(4.3 \%)$ individuals did not use any drugs (Table 2). Diabetes diagnose $(\mathrm{P}=0.021)$, cardiovascular disease $(\mathrm{P}<0.001)$, and "need help with medicines" $(\mathrm{P}=0.022)$ were positively associated with polypharmacy (Table 3 ). Age, sex, place of living, and the diagnoses of cancer, lung disease, and musculoskeletal disease were not significantly associated with polypharmacy.

\section{Potential Drug-Drug Interactions}

In total, 197 individuals used two or more drugs. Among these individuals, 302 pDDIs were identified, affecting $107(54 \%)$ of the individuals. A total number of 132 pDDIs were classified as major pDDIs and these affected $80(41 \%)$ of the individuals (Table 2$)$. Two of the patients, using 10 and 14 different drugs, respectively, were each exposed to six major pDDIs. The total number of drugs was associated with both being exposed to a least one $\mathrm{pDDI}$ and at least one major pDDI $(\mathrm{P}<0.001$, Table 3$)$. 
Table I Socio-Demographic Characteristics of Study Participants $(n=233)$

\begin{tabular}{|l|c|}
\hline Characteristics & Mean士SD \\
\hline Age & $78 \pm 3$ \\
\hline & N (\%) \\
\hline Gender & \\
Male & $107(46)$ \\
Female & $126(54)$ \\
\hline Place of living & \\
Urban & $109(47)$ \\
Rural & $124(53)$ \\
\hline Diagnosis & \\
Hypertension & $120(52)$ \\
Hyperlipidemia & $101(43)$ \\
Eye disease & $50(2 \mathrm{I})$ \\
Arthritis & $4 \mathrm{I}(18)$ \\
Cancer & $34(15)$ \\
Diabetes & $29(12)$ \\
\hline Help with administration of medicines & $33(14)$ \\
Help from home care service & $9(4)$ \\
Help from next-of-kin & $9(4)$ \\
Unspecified & $15(6)$ \\
\hline
\end{tabular}

Abbreviation: SD, standard deviation.

Also, cardiovascular disease was positively associated with being exposed to a pDDI $(\mathrm{P}=0.023)$. Age, sex, place of living, need of help with medicines, and the diagnoses of diabetes, lung disease, musculoskeletal disease, and cancer were not significantly associated with pDDIs.
One individual used a contraindicated combination (isosorbide mononitrate and sildenafil). Among the 132 identified major pDDIs, the drugs most frequently involved were low-dose aspirin (47 times) and simvastatin (32 times) (Table 4). Simvastatin in combination with a calcium channel blocker, amlodipine (17 individuals), verapamil (3 individuals), and diltiazem (1 individual) was the most common pDDI. For aspirin, the most common pDDI was combination with a diuretic (hydrochlorothiazide or loop-diuretic, $n=16$ ). Also, aspirin in combination with other drugs affecting platelet function or coagulation; NSAID (6 individuals), warfarin (1 individual), and clopidogrel (1 individual) was frequently observed. Buprenorphine was the drug most frequently involved in pDDIs considering the number of users, with eight pDDIs in only four individuals (Table 4).

\section{Over-the-Counter Medications}

In total, $61(26 \%)$ of the individuals reported current use of OTC medication. In $95 \%$ of the observations, the OTC drug was a pain reliever, mainly paracetamol which was used by $55(90 \%)$ of the OTC users. Nine of the 11 individuals $(82 \%)$ using ibuprofen were exposed to at least one potential drug-drug interaction involving ibuprofen. In seven of the nine individuals (56\%) with a pDDI involving ibuprofen, the interaction was classified as major. The major pDDIs involving ibuprofen were interactions with aspirin or amitriptyline causing an increased risk of bleeding $(n=3)$ and interactions with thiazide diuretics resulting in loss of diuretic effect $(n=2)$.

Table 2 Polypharmacy and Potential Drug-Drug Interactions in 233 Older Home-Dwellers

\begin{tabular}{|l|c|}
\hline & Median (Range) \\
\hline Number of drugs per patient & $4(0-15)$ \\
\hline & N (\%) \\
\hline $\begin{array}{l}\text { Polypharmacy } \\
\text { Individuals using } \geq 5 \text { drugs }\end{array}$ & $102(43)$ \\
$\quad$ Individuals using $\geq 10$ drugs & $8(3.4)$ \\
\hline $\begin{array}{l}\text { Potential drug-drug interactions } \\
\text { Individuals with potential drug-drug interactions (major and/or moderate) }\end{array}$ & $107\left(54^{\mathrm{a}}\right)$ \\
$\quad \begin{array}{l}\text { Individuals with } \geq 1 \text { major potential drug-drug interactions } \\
\text { Individuals with } \geq 2 \text { major potential drug-drug interaction }\end{array}$ & $80\left(4 I^{\mathrm{a}}\right)$ \\
\hline $\begin{array}{l}\text { Potential drug-drug interactions involving over-the-counter drugs } \\
\text { Individuals with } \geq 1 \text { potential drug-drug interactions (major and/or moderate) } \\
\text { Individuals with } \geq 2 \text { potential drug-drug interactions (major and/or moderate) } \\
\text { Individuals with major potential drug-drug interactions }\end{array}$ & $28\left(16^{\mathrm{b}}\right)$ \\
\hline
\end{tabular}

Notes: ${ }^{a}$ Percentage of number of individuals using $\geq 2$ drugs ( $\left.n=197\right)$. ${ }^{b}$ Percentage of number of individuals using $\geq 3$ drugs ( $n=173$ ). ${ }^{c}$ Percentage of number of users of overthe-counter medicines with a total number of drugs $\geq 2(n=6 \mathrm{I})$. ${ }^{\text {Percentage }}$ of number of users of over-the-counter medicines with a total number of drugs $\geq 3$ ( $\left.n=6 \mathrm{I}\right)$. 
Table 3 Sociodemographic and Clinical Variables Associated with Polypharmacy and Potential Drug-Drug Interactions

\begin{tabular}{|c|c|c|c|c|c|c|c|c|c|}
\hline \multirow[b]{2}{*}{ Variables } & \multicolumn{3}{|c|}{ Polypharmacy } & \multicolumn{3}{|c|}{ Potential Drug-Drug Interaction } & \multicolumn{3}{|c|}{$\begin{array}{l}\text { Major Potential Drug-Drug } \\
\text { Interaction }\end{array}$} \\
\hline & $\begin{array}{l}\operatorname{Exp} \\
(B)^{a}\end{array}$ & $\begin{array}{l}95 \% \mathrm{Cl}^{\mathrm{b}} \text { for } \operatorname{Exp} \\
\text { (B) }\end{array}$ & P-value & $\begin{array}{l}\operatorname{Exp} \\
(B)^{a}\end{array}$ & $\begin{array}{l}95 \% \mathrm{Cl}^{\mathrm{b}} \text { for } \operatorname{Exp} \\
\text { (B) }\end{array}$ & $P$-value & $\begin{array}{l}\operatorname{Exp} \\
(B)^{a}\end{array}$ & $\begin{array}{l}95 \% \mathrm{Cl}^{\mathrm{b}} \text { for } \operatorname{Exp} \\
\text { (B) }\end{array}$ & P-value \\
\hline Age & 1.092 & $0.961-1.240$ & 0.177 & 1.070 & $0.906-1.265$ & 0.424 & 0.983 & $0.854-1.131$ & 0.808 \\
\hline Sex & 1.054 & $0.518-2.144$ & 0.885 & 0.820 & $0.342-1.966$ & 0.657 & 1.169 & $0.5 \mid 4-2.657$ & 0.710 \\
\hline Place of living & 1.683 & $0.796-3.559$ & 0.173 & 0.693 & $0.276-1.739$ & 0.435 & 0.625 & $0.263-1.483$ & 0.286 \\
\hline Drugs (n) & - & - & - & 2.138 & $1.657-2.760$ & $<0.001$ & 1.687 & $1.354-2.102$ & $<0.001$ \\
\hline Help with medicines & 0.330 & $0.128-0.851$ & 0.022 & 1.006 & $0.301-3.363$ & 0.993 & 0.827 & $0.293-2.329$ & 0.719 \\
\hline Diabetes & 3.547 & $1.213-10.372$ & 0.021 & 2.564 & $0.592-11.111$ & 0.208 & 1.250 & $0.435-3.597$ & 0.679 \\
\hline Cardiovascular disease & 5.057 & $2.122-12.05 \mid$ & $<0.001$ & 3.527 & $1.195-10.414$ & 0.023 & 2.256 & $0.772-6.593$ & 0.137 \\
\hline Lung disease & 2.116 & $0.729-6.142$ & 0.168 & 0.274 & $0.07 \mid-1.055$ & 0.060 & 0.681 & $0.215-2.160$ & 0.515 \\
\hline $\begin{array}{l}\text { Musculoskeletal } \\
\text { disease }\end{array}$ & 0.887 & $0.405-1.897$ & 0.738 & 0.982 & $0.292-3.309$ & 0.962 & 0.872 & $0.357-2.133$ & 0.765 \\
\hline Cancer & 2.012 & $0.780-5.188$ & 0.148 & 0.989 & $0.296-3.309$ & 0.977 & 0.706 & $0.245-2.037$ & 0.520 \\
\hline
\end{tabular}

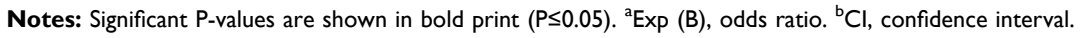

Table 4 Drug Most Frequently Involved in the 132 Major Potential Drug-Drug Interactions (pDDIs) in Older Home-Dwelling Older People Using $\geq 2$ Drugs $(n=197)$

\begin{tabular}{|l|c|c|c|c|}
\hline Drug $^{\mathbf{a}}$ & $\begin{array}{c}\text { Number of Involvements in } \\
\text { pDDIs }\end{array}$ & $\begin{array}{c}\text { Number of Affected } \\
\text { Individuals }\end{array}$ & $\begin{array}{c}\text { Total Number of } \\
\text { Users }\end{array}$ & $\begin{array}{c}\text { Number of pDDIs per } \\
\text { User }\end{array}$ \\
\hline Aspirin & 47 & 32 & 58 & 0.8 \\
Simvastatin & 32 & 31 & 73 & 0.4 \\
Amlodipine & 19 & 19 & 34 & 0.6 \\
Hydrochlorothiazide & 13 & 12 & 26 & 0.5 \\
Warfarin & 11 & 10 & 15 & 0.7 \\
lbuprofen & 8 & 5 & 9 & 0.9 \\
Buprenorphine & 8 & 2 & 4 & 2.0 \\
Diclofenac & 7 & 5 & 6 & 1.2 \\
Metformin & 7 & 6 & 12 & 0.6 \\
Codeine & 6 & 4 & 7 & 0.9 \\
\hline
\end{tabular}

Note: ${ }^{\text {aD }}$ rugs involved in $\leq 5$ pDDls are not listed.

\section{Discussion}

The results of this study demonstrate that almost half of the older home-dwelling individuals use five or more drugs. Few other studies have described the prevalence of polypharmacy in a sample of home-dwellers not restricted to diagnosis or morbidity. However, the results are comparable to three recently published studies. ${ }^{6,7,26}$ Santos et $\mathrm{al}^{6}$ and Novaes et $\mathrm{al}^{7}$ found prevalences of polypharmacy from $26 \%$ to $45 \%$ in home-dwelling older individuals in Brazil, while Wauters et $\mathrm{al}^{26}$ observed a prevalence of approximately $60 \%$ in slightly older individuals (mean age 84) in Belgium. There are several challenges associated with polypharmacy, the main one being drug-drug interactions and risk of adverse events. ${ }^{2-5}$ In agreement with previous findings, a strong association between the number of drugs and drug-drug interaction was also observed in the present study. ${ }^{5}$ Recently, polypharmacy has also been shown to be associated with under-prescribing, and it is speculated that this might be a result of fear of causing harm to the patient through drug-drug interactions and adverse events. ${ }^{27}$

Overall, in the present study pDDIs were detected in $54 \%$ of home-dwelling older individuals using two or more drugs. This was higher than previous findings in similar age groups and settings. ${ }^{6,7}$ Cardiovascular disease was the most common diagnosis in this population and having a cardiovascular diagnose was positively associated with both polypharmacy and pDDIs. This was in agreement with the finding that drugs used to treat cardiovascular disease were most frequently involved in major pDDIs, with simvastatin and aspirin being the two most 
frequent. For simvastatin, the most commonly observed combination was with the calcium channel blocker amlodipine. Concomitant use of these two drugs may lead to increased systemic exposure of simvastatin due to inhibition of CYP3A4 by amlodipine and consequently increased risk of myopathy and rhabdomyolysis. ${ }^{28}$ The risk of rhabdomyolysis is dose-related, and doses of $20 \mathrm{mg}$ or lower of simvastatin are recommended when used concomitantly with amlodipine. ${ }^{29,30}$ The risk of rhabdomyolysis is elevated in older individuals, and there have been several case reports on serious rhabdomyolysis in older individuals where simvastatin has been used in combination with a CYP3A4 inhibitor. $^{31-33}$ In the present study, more than $95 \%$ of statin users were using simvastatin. The high use of simvastatin compared with other statins relates to a decision made by the Norwegian Medicines Agency in 2005 that simvastatin should be the preferred statin to reduce costs for the society. ${ }^{34}$ After 2014, the prescription of statins has not been subjected to restrictions, but many patients have nevertheless continued using simvastatin. The large number of major pDDIs involving simvastatin observed in this study is therefore probably not only a result of the drug-drug interaction potential of simvastatin compared with other statins but also the large use of this drug in the population.

For aspirin, a common major pDDI was combination with drugs causing an additive risk of bleeding. In the present study, both prescribed and OTC NSAIDs are registered, but even so, the reported frequency of the combination of aspirin and an NSAID is lower than previously reported data from the Swedish prescription registry in people $\geq 75$ years. $^{5}$ However, in total, $58 \%$ of the 81 individuals in the present study using antithrombotic treatment (warfarin, aspirin, clopidogrel, or dabigatran) were exposed to a major pDDI. This is similar to the recent finding by Schneider et al, where potentially severe or contraindicated interactions were detected in $58 \%$ of outpatients $\geq 60$ years on antithrombotic therapy. ${ }^{35}$ The high frequencies of major pDDIs in patients on antithrombotic therapy calls for a continuous close monitoring of these patients.

A striking observation in this study was the high prevalence of major pDDIs in patients using buprenorphine. In two of the four individuals using buprenorphine, eight major pDDIs involving buprenorphine were detected. However, these were multimorbid patients using 14 and 8 prescription drugs, respectively. Although the risk of DDIs is known to increase with an increasing number of drugs, the high number of major pDDIs per user involving buprenorphine warrants a close follow-up of patients using this drug. 5

A common feature of many of the pDDIs observed in this study is that a potentially harmful clinical outcome may theoretically be limited by dose adjustments of the affected drug and/or increased monitoring of the patients. No information on the prescribers was collected in this study, and consequently, information on precautions like dose adjustments or close follow-up of the patients was not available. However, the relatively high prevalence of major pDDIs might indicate that medication reviews should be performed more frequently. Currently, in Norway, a legal regulation calls for yearly medication reviews in patients where the regular general practitioner finds it necessary, but data on how often this is performed in practice is not available. Also, it is known from previous research that medication records are incomplete or contain errors in more than half of the cases in both primary and secondary health care, which complicates the work with identifying pDDIs. ${ }^{36,37}$

Nine of the 11 individuals using OTC ibuprofen, used it in combination with a prescription drug resulting in a pDDIs causing increased risk of bleeding (aspirin, tricyclic antidepressants) or affecting renal function (diuretics). Although the risk of GI bleeding has not been studied specifically for OTC NSAIDs, there is a large body of evidence showing that GI bleedings associated with NSAID use increases with increasing age and use of multiple NSAIDs, including low dose aspirin. $^{38}$ The fact that $82 \%$ of the older individuals that used ibuprofen also used an interacting prescription drug, could be due to unawareness of the potentially harmful effects of OTC analgesics. Previous studies have shown that there is a general misperception among older adults that OTC drugs are too weak to cause any harm $^{39}$ and that the awareness of pDDIs is higher in younger compared with older individuals. ${ }^{40}$ Safe use of OTC drugs is complicated by the fact that, typically, the regular general practitioner is not informed about the patients' use of OTC drugs as these are generally not registered in the electronic patient records, and therefore the risk of prescribing an interacting drug increases. ${ }^{20}$ Improved labeling of OTC analgesics, as suggested by Roumie and co-workers, could potentially reduce the use of OTC NSAIDs in patients at risk, or may lead to patients informing the regular general practitioner about their OTC drug use. ${ }^{39}$ Also, for patients receiving home 
care services or preventive home visits, information about the patients' use of OTC drugs could be communicated to the regular general practitioner by the nurse performing the visit. ${ }^{41}$

A limitation to the present study is the relatively limited variance in age among the included participants, which might explain the lack of association between age and polypharmacy observed in this study. The study is strengthened by the fact that information on drug use is based on more than one source of information. In addition to medication lists from the general practitioner or home care service where this was available, information on drug use was also collected through interviews with the patients themselves and their next-of-kin and visual inspection of actual medication in use. This increases the possibility of getting more complete information as it is known from previous research that medication lists frequently contain errors. ${ }^{36}$ Unfortunately, the general practitioners were not contacted and data on possible precautions (dose adjustments, closer follow-up) and clinical outcome of the pDDI are therefore lacking. Information on clinical outcome would have strengthened the study further. The response rate was around $60 \%$ and the main reason given for declining participation was no need for a preventive home visit. Unfortunately, characteristics of the individuals who declined participation were not collected and, thus, a possible selection bias cannot be ruled out. ${ }^{21}$ It is possible that the presented data represent individuals with a higher disease burden and drug use than the general population in this region. However, health status in terms of self-rated health in the participants was comparable to other large-scale European epidemiological studies, indicating a representative sample. $^{42-44}$

\section{Conclusion}

This study revealed a high prevalence of polypharmacy and pDDIs with both prescription and non-prescription drugs in older home-dwelling individuals. Close monitoring of the patients at risk of pDDIs, increased awareness of the potential of OTC drugs to cause DDIs, and good communication between the general practitioner and patient is needed, to reduce the risk related to $\mathrm{pDDI}$.

\section{Abbreviations}

DDI, drug-drug interaction; NSAID, non-steroid antiinflammatory drug; OTC, over the counter; pDDI, potential drug-drug interaction.

\section{Data Sharing Statement}

The dataset is available from the corresponding author upon a reasonable request.

\section{Ethics Approval and Informed Consent}

The study was approved by the Norwegian Data Protection Services (no. 26328 and 44970). Informed consent was obtained from all individuals included in the study. The study was conducted in accordance with the Declaration of Helsinki.

\section{Acknowledgments}

The contributions of Karen Johanne Vae and Dag-Helge Rønnevik are greatly acknowledged.

\section{Author Contributions}

$\AA \mathrm{S}$ and BSC initiated and designed the project with contributions from NC, LK, and MW. BSC was responsible for the development of the data collection tool with contributions from NC, LK, AF, MW, KF, KS, ÅS. AF collected data (performed home visits). KF trained and advised nurses that performed home visits. All authors contributed to data analysis, drafting or revising the article, have agreed on the journal to which the article will be submitted, gave final approval of the version to be published, and agree to be accountable for all aspects of the work.

\section{Funding}

The planning and conduct of the study, as well as manuscript preparation, was done without external funding.

\section{Disclosure}

None of the authors has any conflicts of interest or competing interests to declare.

\section{References}

1. Drug consumption statistics 2013-2017. Norwegian prescription database; 2018. Available from: https://www.fhi.no/en/publ/2018/legemiddelstatis tikk-20182-reseptregisteret-20132017. Accessed December 11, 2020.

2. Kongkaew C, Noyce PR, Ashcroft DM. Hospital admissions associated with adverse drug reactions: a systematic review of prospective observational studies. Ann Pharmacother. 2008;42(7-8):1017-1025. doi:10.1345/aph.1L037

3. Ebbesen J, Buajordet I, Erikssen J, et al. Drug-related deaths in a department of internal medicine. Arch Intern Med. 2001;161 (19):2317-2323. doi:10.1001/archinte.161.19.2317

4. Becker ML, Kallewaard M, Caspers PW, Visser LE, Leufkens HG, Stricker BH. Hospitalisations and emergency department visits due to drug-drug interactions: a literature review. Pharmacoepidemiol Drug Saf. 2007;16(6):641-651. doi:10.1002/pds.1351 
5. Johnell K, Klarin I. The relationship between number of drugs and potential drug-drug interactions in the elderly: a study of over 600,000 elderly patients from the Swedish prescribed drug register. Drug Saf. 2007;30 (10):911-918. doi:10.2165/00002018-200730100-00009

6. Santos TRA, Silveira EA, Pereira LV, Provin MP, Lima DM, Amaral RG. Potential drug-drug interactions in older adults: a population-based study. Geriatr Gerontol Int. 2017;17 (12):2336-2346. doi:10.1111/ggi.13070

7. Novaes PH, da Cruz DT, Lucchetti ALG, Leite ICG, Lucchetti G. The "iatrogenic triad": polypharmacy, drug-drug interactions, and potentially inappropriate medications in older adults. Int $J$ Clin Pharm. 2017;39(4):818-825. doi:10.1007/s11096-017-0470-2

8. Hoffmann W, van den Berg N, Thyrian JR, Fiss T. Frequency and determinants of potential drug-drug interactions in an elderly population receiving regular home visits by GPs-results of the home medication review in the AGnES-studies. Pharmacoepidemiol Drug Saf. 2011;20(12):1311-1318. doi:10.1002/pds.2224

9. Bjerrum L, Andersen M, Petersen G, Kragstrup J. Exposure to potential drug interactions in primary health care. Scand J Prim Health Care. 2003;21(3):153-158. doi:10.1080/02813430310001806

10. Qato DM, Wilder J, Schumm LP, Gillet V, Alexander GC. Changes in prescription and over-the-counter medication and dietary supplement use among older adults in the United States, 2005 vs 2011. JAMA Intern Med. 2016;176(4):473-482. doi:10.1001/jamainternmed.2015.8581

11. Lovdata. Forskrift om fastlegeordning i kommunene. [Regulation on regular general practitioners in the municipalities]. Available from: https://lovdata.no/dokument/SF/forskrift/2012-08-29-842?q=forskrift fastlege. Accessed December 11, 2020. Norwegian.

12. O'Sullivan D, O'Mahony D, O'Connor MN, et al. Prevention of adverse drug reactions in hospitalised older patients using a software-supported structured pharmacist intervention: a cluster randomised controlled trial. Drugs Aging. 2016;33(1):63-73. doi:10.1007/s40266-015-0329-y

13. Andersson ML, Bottiger Y, Lindh JD, Wettermark B, Eiermann B. Impact of the drug-drug interaction database SFINX on prevalence of potentially serious drug-drug interactions in primary health care. Eur $J$ Clin Pharmacol. 2013;69(3):565-571. doi:10.1007/s00228-012-1338-y

14. Hanlon JT, Perera S, Newman AB, et al. Potential drug-drug and drugdisease interactions in well-functioning community-dwelling older adults. J Clin Pharm Ther. 2017;42(2):228-233. doi:10.1111/jcpt.12502

15. Nilsson N, Lea M, Lao Y, et al. Medication discrepancies revealed by medication reconciliation and their potential short-term and long-term effects: a Norwegian multicentre study carried out on internal medicine wards. EJHP. 2015;22(5):298-303.

16. Ryvarden E, Sivertsen ØS. Langt frem til en innbygger- en journal. [A long way to go to One citizen-one patient record]. Tidskr Nor Legeforen. 2018;13. Norwegian.

17. Poole C, Jones D, Veitch B. Relationships between prescription and non-prescription drug use in an elderly population. Arch Gerontol Geriatr. 1999;28(3):259-271. doi:10.1016/S0167-4943(99)00013-8

18. Goh LY, Vitry AI, Semple SJ, Esterman A, Luszcz MA. Selfmedication with over-the-counter drugs and complementary medications in South Australia's elderly population. BMC Complement Altern Med. 2009;9(1):42. doi:10.1186/1472-6882-9-42

19. Dechanont S, Maphanta S, Butthum B, Kongkaew C. Hospital admissions/visits associated with drug-drug interactions: a systematic review and meta-analysis. Pharmacoepidemiol Drug Saf. 2014;23 (5):489-497. doi:10.1002/pds.3592

20. Olesen C, Harbig P, Barat I, Damsgaard EM. Absence of 'over-thecounter' medicinal products in on-line prescription records: a risk factor of overlooking interactions in the elderly. Pharmacoepidemiol Drug Saf. 2013;22(2):145-150. doi:10.1002/pds.3362

21. Seiger Cronfalk B, Fjell A, Carstens N, et al. Health team for the elderly: a feasibility study for preventive home visits. Prim Health Care Res Dev. 2017;18(3):242-252. doi:10.1017/S1463423 617000019
22. Fung KW, Kapusnik-Uner J, Cunningham J, Higby-Baker S, Bodenreider O. Comparison of three commercial knowledge bases for detection of drug-drug interactions in clinical decision support. J Am Med Inform Assoc. 2017;24(4):806-812. doi:10.1093/jamia/ ocx 010

23. Kheshti R, Aalipour M, Namazi S. A comparison of five common drug-drug interaction software programs regarding accuracy and comprehensiveness. $J$ Res Pharm Pract. 2016;5(4):257-263. doi:10.4103/2279-042X.192461

24. IBM Micromedex ${ }^{\circledR}$. Drug interaction checking (electronic version). Greenwood Village, Colorado, USA: IBM Watson Health. Available from: https://www.micromedexsolutions.com/. Accessed January 21, 2021.

25. Masnoon N, Shakib S, Kalisch-Ellett L, Caughey GE. What is polypharmacy? A systematic review of definitions. BMC Geriatr. 2017;17 (1):230. doi:10.1186/s12877-017-0621-2

26. Wauters M, Elseviers M, Vaes B, et al. Polypharmacy in a Belgian cohort of community-dwelling oldest old (80+). Acta Clin Belg. 2016;71(3):158-166. doi:10.1080/17843286.2016.1148298

27. Cadogan CA, Ryan C, Hughes CM. Appropriate polypharmacy and medicine safety: when many is not too many. Drug Saf. 2016;39 (2):109-116. doi:10.1007/s40264-015-0378-5

28. Omar MA, Wilson JP. FDA adverse event reports on statin-associated rhabdomyolysis. Ann Pharmacother. 2002;36(2):288-295. doi:10.1345/aph.1A289

29. Chaturvedula A, Sale ME, Lee H. Genetic algorithm guided population pharmacokinetic model development for simvastatin, concurrently or non-concurrently co-administered with amlodipine. J Clin Pharmacol. 2014;54(2):141-149. doi:10.1002/jcph.176

30. Son H, Lee D, Lim LA, Jang SB, Roh H, Park K. Development of a pharmacokinetic interaction model for co-administration of simvastatin and amlodipine. Drug Metab Pharmacokinet. 2014;29 (2):120-128. doi:10.2133/dmpk.DMPK-13-RG-053

31. Karnik NS, Maldonado JR. Antidepressant and statin interactions: a review and case report of simvastatin and nefazodone-induced rhabdomyolysis and transaminitis. Psychosomatics. 2005;46 (6):565-568. doi:10.1176/appi.psy.46.6.565

32. Molden E, Andersson KS. Simvastatin-associated rhabdomyolysis after coadministration of macrolide antibiotics in two patients. Pharmacotherapy. 2007;27(4):603-607. doi:10.1592/phco.27.4.603

33. Page SR, Yee KC. Rhabdomyolysis in association with simvastatin and dosage increment in clarithromycin. Intern Med J. 2014;44 (7):690-693. doi:10.1111/imj.12464

34. Bakken C. Forskrivning av foretrukne legemidler. [Prescription of preferred drugs]. Tidskr nor Laegeforen. 2005;22:125. Norwegian.

35. Schneider KL, Kastenmuller K, Weckbecker K, Bleckwenn M, Bohme M, Stingl JC. Potential drug-drug interactions in a cohort of elderly, polymedicated primary care patients on antithrombotic treatment. Drugs Aging. 2018;35(6):559-568. doi:10.1007/s40266018-0550-6

36. Tam VC, Knowles SR, Cornish PL, Fine N, Marchesano R, Etchells EE. Frequency, type and clinical importance of medication history errors at admission to hospital: a systematic review. CMAJ. 2005;173(5):510-515. doi:10.1503/cmaj.045311

37. Rognstad S, Staand J. Do general practitioners know what medication community nurses give their shares patients? Tidsskr nor Laegeforen. 2004;18(124):810-812.

38. Tielemans MM, Eikendal T, Jansen JB, van Oijen MG. Identification of NSAID users at risk for gastrointestinal complications: a systematic review of current guidelines and consensus agreements. Drug Saf. 2010;33(6):443-453. doi:10.2165/11534590000000000-00000

39. Roumie CL, Griffin MR. Over-the-counter analgesics in older adults: a call for improved labelling and consumer education. Drugs Aging. 2004;21(8):485-498. doi:10.2165/00002512-200421080-00001 
40. Indermitte J, Reber D, Beutler M, Bruppacher R, Hersberger KE. Prevalence and patient awareness of selected potential drug interactions with self-medication. J Clin Pharm Ther. 2007;32(2):149-159. doi:10.1111/j.1365-2710.2007.00809.x

41. Lagerin A, Carlsson AC, Nilsson G, Westman J, Tornkvist L. District nurses' preventive home visits to 75-year-olds: an opportunity to identify factors related to unsafe medication management. Scand $J$ Public Health. 2014;42(8):786-794. doi:10.1177/140349481 4550680

42. Fjell A, Cronfalk BS, Carstens N, et al. Risk assessment during preventive home visits among older people. J Multidiscip Healthc. 2018;11:609-620. doi:10.2147/JMDH.S176646
43. Olofsson J, Padyab M, Malmberg G. Health disparities in Europe's ageing population: the role of social network. Glob Health Action. 2018;11(1):1445498. doi:10.1080/16549716.2018.1445498

44. Storeng SH, Sund ER, Krokstad S. Factors associated with basic and instrumental activities of daily living in elderly participants of a population-based survey: the Nord-Trondelag Health Study, Norway. BMJ Open. 2018;8(3):e018942. doi:10.1136/bmjopen2017-018942

\section{Publish your work in this journal}

The Journal of Multidisciplinary Healthcare is an international, peerreviewed open-access journal that aims to represent and publish research in healthcare areas delivered by practitioners of different disciplines. This includes studies and reviews conducted by multidisciplinary teams as well as research which evaluates the results or conduct of such teams or healthcare processes in general. The journal covers a very wide range of areas and welcomes submissions from practitioners at all levels, from all over the world. The manuscript management system is completely online and includes a very quick and fair peer-review system. Visit http://www.dovepress.com/testimonials. php to read real quotes from published authors. 